\title{
The correlation between point-of-care ultrasound and digital tomosynthesis when used with suspected COVID-19 pneumonia patients in primary care
}

Pablo Fabuel Ortega ${ }^{1}$ (D) Noelia Almendros Lafuente ${ }^{1}$, Sandra Cánovas García², Laura Martínez Gálvez a and Aurora González-Vidal ${ }^{3^{*}}$

\begin{abstract}
Background: The use of lung ultrasound (LU) with COVID-19 pneumonia patients should be validated in the field of primary care (PC). Our study aims to evaluate the correlation between $L U$ and radiographic imaging in $P C$ patients with suspected COVID-19 pneumonia.

Methods: This observational, prospective and multicentre study was carried out with patients from a PC health area whose tests for COVID-19 and suspected pneumonia had been positive and who then underwent LU and a digital tomosynthesis (DT). Four PC physicians obtained data regarding the patients'symptoms, examination, medical history and ultrasound data for 12 lung fields: the total amount of B lines (zero to four per field), the irregularity of the pleural line, subpleural consolidation, lung consolidation and pleural effusion. These data were subsequently correlated with the presence of pneumonia by means of DT, the need for hospital admission and a consultation in the hospital emergency department in the following 15 days.
\end{abstract}

Results: The study was carried out between November 2020 and January 2021 with 70 patients (40 of whom had pneumonia, confirmed by means of DT). Those with pneumonia were older, had a higher proportion of arterial hypertension and lower oxygen saturation $\left(\mathrm{sO}_{2}\right)$. The number of $\mathrm{B}$ lines was higher in patients with pneumonia (16.53 vs. $4.3, p<0.001)$. The area under the curve for LU was 0.87 ( $95 \% \mathrm{Cl} 0.78-0.96, p<0.001)$, and when establishing a cutoff point of six B lines or more, the sensitivity was $0.875(95 \% \mathrm{Cl} 0.77-0.98, p<0.05)$, the specificity was $0.833(95 \% \mathrm{Cl}$ $0.692-0.975, p<0.05)$, the positive-likelihood ratio was 5.25 (95\% Cl 2.34-11.79, $p<0.05$ ) and the negative-likelihood ratio was 0.15 ( $95 \% \mathrm{Cl} 0.07-0.34, p<0.05)$. An age of $\geq 55$ and a higher number of $\mathrm{B}$ lines were associated with admission. Patients who required admission $(n=7)$ met at least one of the following criteria: $\geq 55$ years of age, $\mathrm{sO}_{2} \leq 95 \%$, presence of at least one subpleural consolidation or $\geq 21 \mathrm{~B}$ lines.

Conclusions: LU has great sensitivity and specificity for the diagnosis of COVID-19 pneumonia in PC. Clinical ultrasound findings, along with age and saturation, could, therefore, improve decision-making in this field.

Keywords: Coronavirus infection, Ultrasonography, Family practice, Pneumonia, Radiography, Thoracic

\footnotetext{
*Correspondence: aurora.gonzalez2@um.es

${ }^{3}$ Department of Information and Communication Engineering Faculty

of Computer Sciences, University of Murcia, Murcia, Spain

Full list of author information is available at the end of the article
}

\section{Introduction}

During the recent SARS-CoV-2 (severe acute respiratory syndrome coronavirus 2) pandemic, lung ultrasound (LU) has been a useful tool in the diagnosis and 
management of COVID-19 pneumonia (coronavirus disease 2019) [1].

The low sensitivity of chest radiography has led to the proposal that computed tomography $(\mathrm{CT})$ could be used as the gold standard [2]. However, the limited access to it, its risk of radiation and the saturation of diagnostic imaging services signifies that there is a growing need to carefully consider its indication [3] and to seek alternatives by which to identify the existence of lung damage and its severity.

Digital tomosynthesis (DT) and LU have, therefore, been proposed as means to improve the diagnostic precision of chest radiography [4-11]. DT is considered to be an emerging application that has some of the tomographic benefits of $\mathrm{CT}$, since it provides multiple anatomic images, but has a lower cost and radiation dose [12]. It is normally used as a diagnostic tool for breast cancer, but has nevertheless been shown to be not only useful in lung pathologies, but also better than simple chest radiography in the case of pulmonary nodules or cystic fibrosis, as it reduces superposition artefacts and improves resolution [13, 14]. Given this, it could improve the diagnostic value of chest radiography with regard to assessing COVID-19 lung involvement [4]. With regard to $\mathrm{LU}$, it has also proved to be useful and to have a good correlation with CT $[6,7]$ and to be superior to chest radiography [8]. However, although LU has been proposed as a means to optimise primary care (PC) patients' well-being [9], most studies concerning its sensitivity and specificity have been carried out in a hospital setting [10, $11]$.

The objective of this study is to evaluate the correlation between LU and DT in PC patients with suspected COVID-19 pneumonia. A description of the demographic, clinical, ultrasound and radiological characteristics of patients with suspected COVID-19 pneumonia and its clinical course is also provided.

\section{Methods}

\section{Design, population and organisational context}

This was a prospective, descriptive and multicentre observational study of the correlation of ultrasoundDT in PC patients under telephonic follow-up for active COVID-19 infection confirmed by a diagnostic test (SARS-CoV-2 antigen test or polymerase chain reaction test). There was the clinical suspicion of pneumonia, and the use of an imaging test was indicated for its diagnosis.

The population corresponds to the VI Health Area (Vega Media del Segura) of the Region of Murcia, Spain, which covers a population of 260,820 people and is made up of 15 health centres [15]. As inclusion criteria, we considered patients of 18 and over that were clinically suspected of having COVID-19 pneumonia during follow-up by their PC physicians. These patients were subsequently referred for diagnostic confirmation by means of DT, which took place thanks to the specific high-resolution circuit between $\mathrm{PC}$ and the radiology service (AP-Rx). They additionally had a clinical or baseline situation that allowed the performance of $\mathrm{LU}$ in a sitting position, after their informed consent had been obtained. Those patients with haemodynamic instability, a previous diagnosis of pneumonia in the last 3 months or difficulty in complying with the safety standards for the prevention of COVID-19 infection were excluded.

The protocol for DT referral in our health area included those symptoms related to lung involvement: dyspnoea, tachypnoea, fever for 4 days or any symptom related to hypoxia (confusion, hypotension, cyanosis, anuria or chest pain).

In our health area, a high-resolution circuit was established between the $\mathrm{PC}$ and the radiology department (AP-Rx) during the first wave of the pandemic in March 2020. This circuit allows direct referral from PC in order to perform DT on patients with the clinical suspicion of COVID-19 pneumonia in less than $24 \mathrm{~h}$. The patients are given appointments in a specific COVID circuit and the images obtained are immediately reported by a radiologist. If the results of the DT are normal, the patients are sent home again for PC follow-up. If, however, COVID19 pneumonia is confirmed, they are referred to the Emergency Department (ED) [16].

This study was approved by the Hospital Morales Meseguer Clinical Research Ethics Committee (EST code: $51 / 20$ ) and was carried out after informed consent had been obtained.

\section{Data}

Data were collected by four researchers, who were 4th year resident Family and Community Medicine interns with 2 months of specific training in LU. They were organised in pairs on a 5 -h working day, 2 days a week, until the entirety of the desired sample had been obtained. One of the researchers consecutively selected the patients who met the inclusion criteria after conducting the DT and then directed them to a specific room, next to the DT room, where a second researcher conducted the clinical interview and the LU (Fig. 1).

The first researcher instructed the patients not to mention any data that could reveal the result of the DT, such that the second researcher was unaware of it at all times. This, therefore, ensured that the second had no knowledge of the DT results, in order to eliminate possible bias.

The technique was performed while the patient was seated, using the SIEMENS ACUSON Freestyle ${ }^{\mathrm{TM}}$ ultrasound machine and the $3.5-5 \mathrm{MHz}$ convex probe. Twelve thoracic areas were systematically evaluated, six 


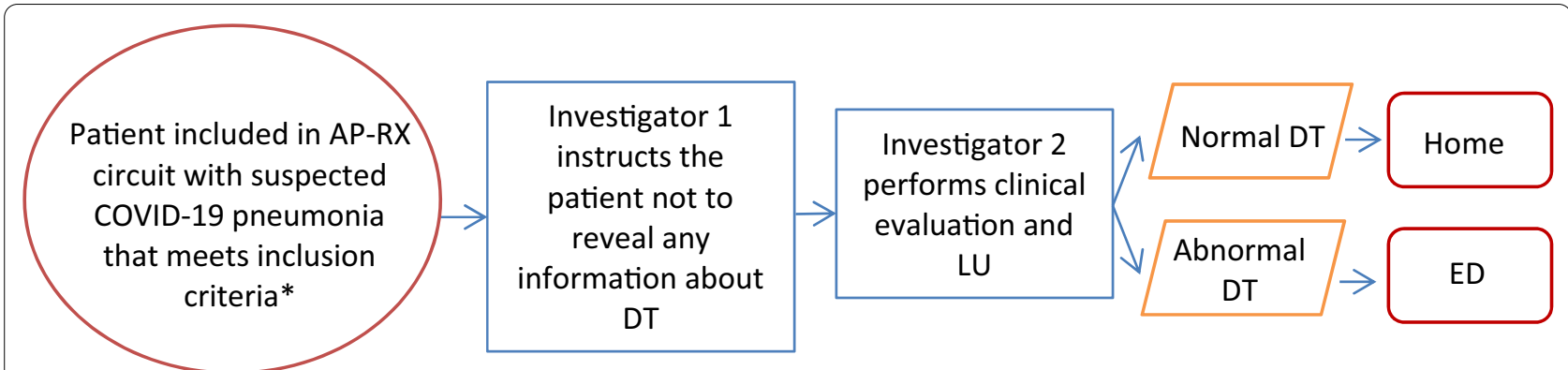

Fig. 1 Patient flow diagram describing patient recruitment process. *Patients were recruited consecutively once Investigator 2 finished the evaluation with the previous patient. AP-RX specific high-resolution circuit between PC and the radiology department, DT digital tomosynthesis, $L U$ lung ultrasound, ED emergency department

in each hemithorax (see Fig. 2) and in a similar manner to that proposed in other studies $[6,7,10]$. The exploration technique in each field, in order from 1 to 12 , consisted of a longitudinal and an oblique-transverse section, sweeping both the cranio-caudal and mediolateral in all the intercostal spaces (the "mowing the lawn" technique).

During the LU, the researcher also employed state-ofthe-art procedures $[9,17-19]$ to collect each patient's demographic data, personal history, symptoms and the findings obtained from the physical and ultrasound examination. Finally, the result of the DT and the patient's destination were noted.
The main variable employed was the number of B lines, which were categorised as follows for each lung field: "0 lines" when there was no B line, "1 B line" when there was a B line, "2 B lines" when there were two B lines, " 3 B lines" when there were three $B$ lines and " 4 B lines" when four or more B lines were found or there was a confluence of them. The presence of an irregularity of the pleural line, subpleural consolidation, lung consolidation and pleural effusion was also recorded. The computerised medical history was used to verify whether the patients had been admitted, sent to the ED for a consultation, or required a new $\mathrm{DT}$, as requested by their $\mathrm{PC}$ physician, in the following 15 days. The Brixia Index was also collected

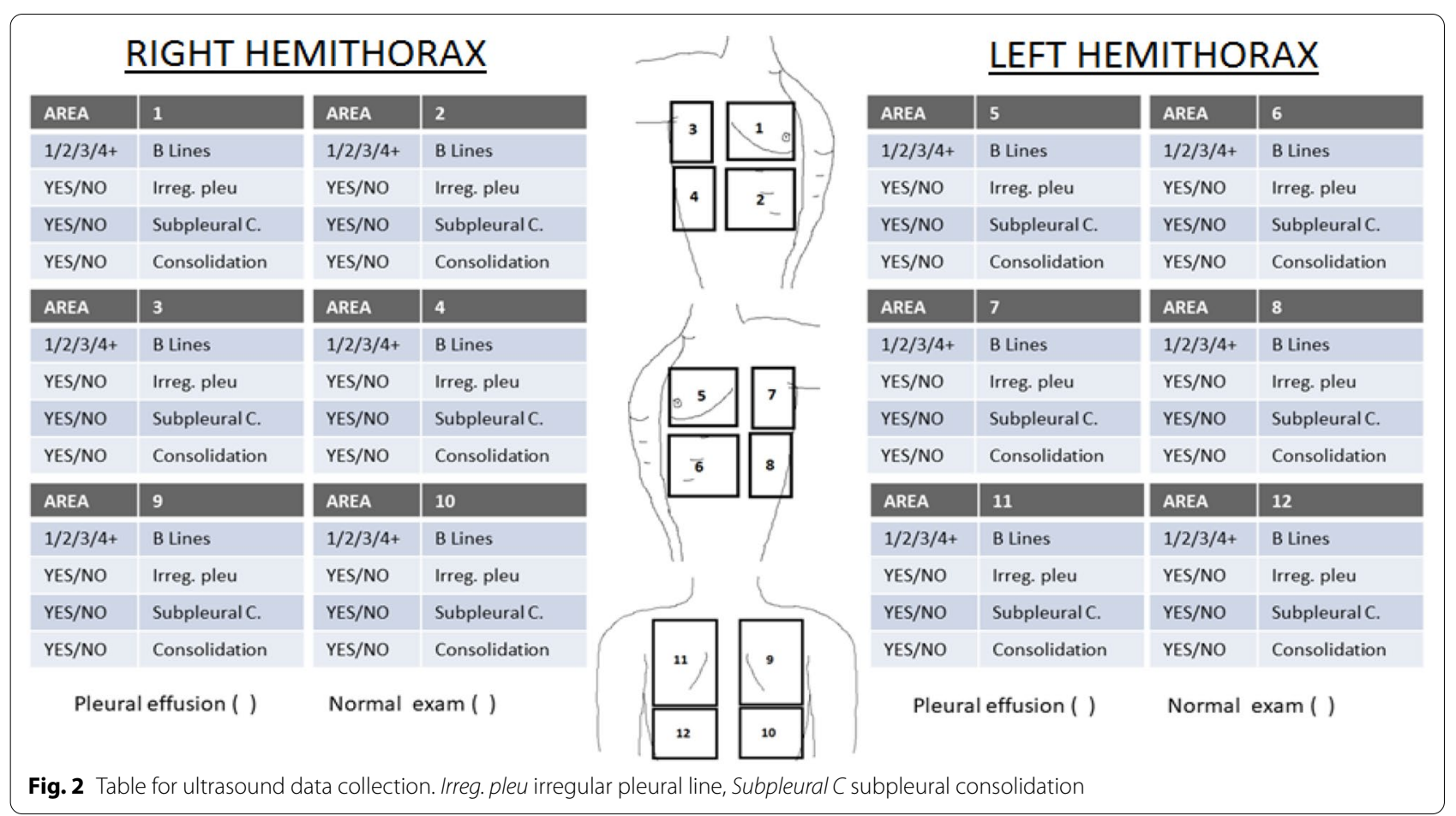


as a valid prognostic marker, together with other predictors of in-hospital mortality [20, 21]. Epidemiological data were also collected in order to contribute to a better understanding of our results.

\section{Statistical analysis}

With regard to the statistical analysis, the $\chi^{2}$ statistical test was used for qualitative variables, while Fisher's exact test was employed for samples smaller than 5 in the contingency table or $<20 \%$ as regards the expected variables. With regard to the quantitative variables, we used the Student's $t$-test if they had a normal distribution or the Mann-Whitney $U$ test otherwise (using the Kolmogorov-Smirnov test). The one-sample $t$-test was used on an individual basis to calculate the confidence interval of the means, since many authors of the literature consulted consider that 30 is a sufficient sample in order to be able to use this method [22]. When normality could not be assumed, the differences between the study groups were tested using the Mann-Whitney $U$ test. A level of statistical significance of $p<0.05$ was established.

As a complement to this analysis, a representation of the receiver operating characteristic curve (ROC) was carried out in order to discover the cut-off point in our dependent variable with a determined sensitivity $(S)$, specificity (Sp), positive predictive value (PPV), negative
Table 1 Cohen's Kappa coefficient categorisation

\begin{tabular}{ll}
\hline Values of Kappa & Categorisation \\
\hline 0.00 & No agreement \\
$0.01-0.2$ & Poor agreement \\
$0.21-0.40$ & Fair agreement \\
$0.41-0.60$ & Moderate agreement \\
$0.61-0.80$ & Substantial agreement \\
$0.81-1.00$ & Almost perfect agreement \\
\hline
\end{tabular}

predictive value (NPV), odds ratio (OR), positive-likelihood ratio (+LR) and negative-likelihood ratio (-LR). The IBM SPSS Statistics V.25 computer program and the $\mathrm{R}$ statistical program were used for this purpose. A sample size of 69 was calculated, with a significance level of 0.05 and a statistical power of 0.8 .

\section{Inter-observer reliability}

Prior to data collection, a study of reliability was conducted by the four researchers who carried out the LU. This was conducted with 16 lung clips selected by an external collaborator who was an expert in ultrasound. The degree of agreement among them was measured using Cohen's Kappa coefficient. The Kappa coefficient was assessed by employing the Landis and

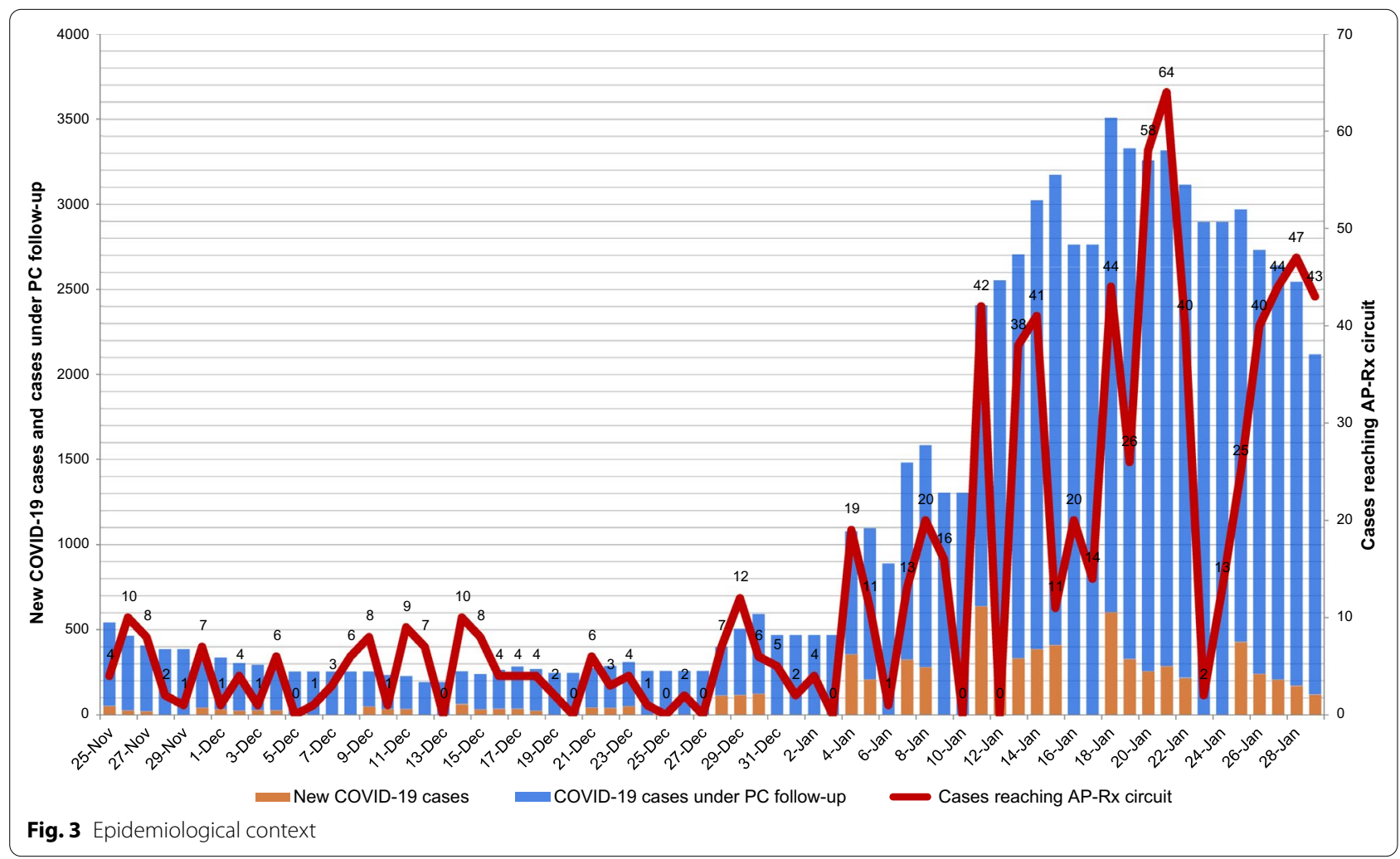




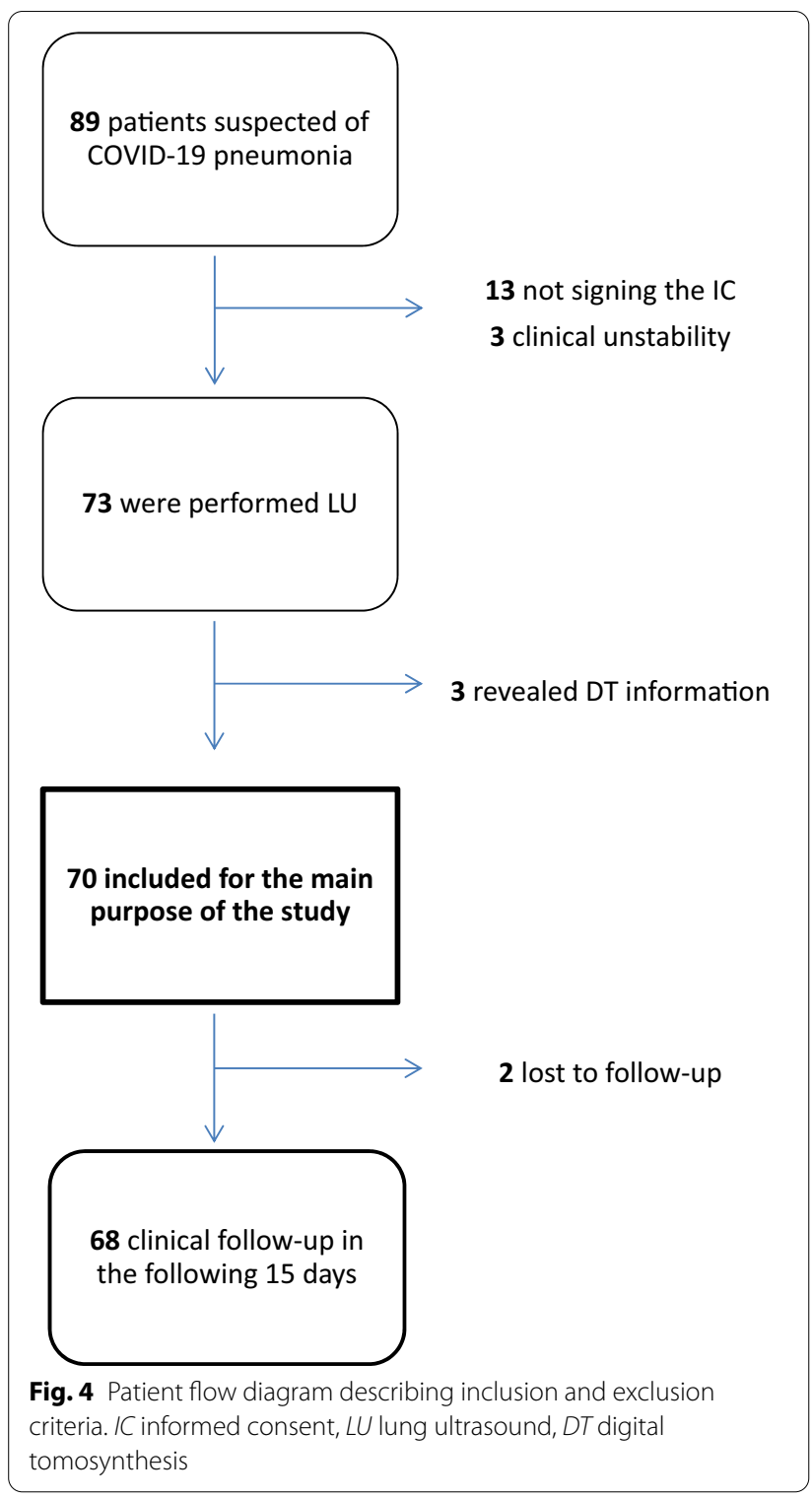

Koch categorisation, 1977 (Table 1) [23]. The results obtained from the Kappa coefficient ranged between 0.45 and 1. Agreements between 0.61 and 0.80 (considerable agreement) accounted for $37.5 \%$, and $>0.8$ (almost perfect) accounted for $33.5 \%$, signifying that $71 \%$ of the agreements were sufficiently valid to be used in the study.

\section{Results}

\section{Epidemiological context}

Our study period, which ranged between the 25th of November 2020 and the 29th of January 2021, included the highest 14-day cumulative number of cases per 100,000 inhabitants (from 20.3 in the period 9th to 23rd of December, to 718.12 from 7 th to 21 st of January), in addition to the highest number of patients on the AP-Rx circuit per day (Fig. 3).

\section{Clinical features}

The initial assessment was carried out with 89 patients, 13 of whom were excluded because they had not signed the informed consent, 3 owing to clinical instability and 3 owing to the fact that the 'blind' nature of their DT results was compromised. This signifies that 70 patients (35 of whom were women) of between 22 and 98 years of age and from the 15 health centres in the area (100\%) were eventually included in the study (Fig. 4). The distribution by sex and age, along with the clinical characteristics of the patients, is shown in Table 2 and Fig. 5.

A total number of 40 patients were diagnosed as having pneumonia by means of DT (57.14\%). The patients with pneumonia were older, had a higher proportion of arterial hypertension and a lower $\mathrm{sO}_{2}$ (Table 3). There was a higher non-significant proportion of men $(60 \%)$ with an OR of $1.58(p=0.053)$. Patients over 55 had pneumonia with an OR of $2.75(p=0.049)$. Only one patient $(1.4 \%)$ had a diagnosis additional to that of pneumonia (lung granuloma).

\section{Ultrasound correlation and COVID-19 pneumonia}

The mean sum of the $B$ lines of all the fields of those patients who were diagnosed as having pneumonia by means of DT $(16.53$, 95\% CI 13.23-19.81) was significantly higher than those who did not have pneumonia (4.3, 95\% CI 2.04-6), with $p<0.001$. The area under the curve (AUC) was 0.87 (95\% CI $0.78-0.96, p<0.001$ ), and when establishing a cut-off point of six B lines or more, the $S$ was 0.875 ( $95 \%$ CI $0.77-0.98, p<0.05$ ), the Sp was 0.833 (95\% CI $0.692-0.975, p<0.05$ ), the PPV was $0.875(95 \%$ CI $0.77-0.98, p<0.05)$ and the NPV was 0.833 (95\% CI $0.692-0.975, p<0.05)$ for the diagnosis of COVID pneumonia (Table 4 and Fig. 6). The +LR was 5.25 (95\% CI 2.34-11.79) and the -LR (-LR) was 0.15 (95\% CI 0.07-0.34). No significant differences between men and women or age groups were found in the subgroup analysis.

Of the 40 patients with pneumonia (27.5\%), 11 had no field with four or more B lines and 29 (72.5\%) had at least one. Of the 30 patients without pneumonia (16.7\%), 5 had a field with four or more B lines and 25 (83.3\%) did not have any fields with four or more B lines. The main ultrasound findings according to the presence of pneumonia are shown in Table 4.

There were 11 patients with at least one subpleural consolidation in one field, and pneumonia was found in all of them when employing DT. With regard to the irregularity of the pleural line, when selecting only 
Table 2 Patient distribution by sex and clinical characteristics

\begin{tabular}{|c|c|c|c|c|}
\hline Variable & $n(\%)$ & $n(\%)$ & Total & $\begin{array}{l}\text { Differences } \\
\text { between men and } \\
\text { women }\end{array}$ \\
\hline Sex & Men $n=35(50 \%)$ & Women $n=35(50 \%)$ & 70 & \\
\hline Age & $56.11(51.84-60.39)$ & $48.2(43.50-52.90)$ & 52.16 & $p=0.014$ \\
\hline Pneumonia & $24(68 \%)$ & $16(45.7 \%)$ & $40(57.14 \%)$ & NS \\
\hline Arterial hypertension & $13(37.1 \%)$ & $7(20 \%)$ & $20(28.6 \%)$ & NS \\
\hline Diabetes mellitus & $6(17.1 \%)$ & $2(5.7 \%)$ & $8(11.4 \%)$ & NS \\
\hline Dyslipidaemia & $8(22.9 \%)$ & $4(11.4 \%)$ & $12(17.1 \%)$ & NS \\
\hline Smoker & $9(25.7 \%)$ & $4(11.4 \%)$ & $13(18.6 \%)$ & NS \\
\hline COPD/asthma & $7(20.0 \%)$ & $8(22.9 \%)$ & $15(21.4 \%)$ & NS \\
\hline Cardiopathy/chronic heart failure & $5(14.3 \%)$ & $2(5.7 \%)$ & $7(10 \%)$ & NS \\
\hline Days from the onset of symptoms & 8.57 & 10.06 & 9.31 & NS \\
\hline Fever & $22(62.9 \%)$ & $18(51.4 \%)$ & $40(57.1 \%)$ & NS \\
\hline Dyspnoea & $19(54.3 \%)$ & $20(57.1 \%)$ & $39(55.7 \%)$ & NS \\
\hline Cough & $26(74.3 \%)$ & $27(77.1 \%)$ & $53(75.7 \%)$ & NS \\
\hline Expectoration & $8(22.9 \%)$ & $6(17.1 \%)$ & $14(20 \%)$ & NS \\
\hline Pathological lung auscultation & $11(31.4 \%)$ & $9(25.7 \%)$ & $20(28.6 \%)$ & NS \\
\hline Oxygen saturation & $96.10(95.2-97.01)$ & $97.24(96.78-97.8)$ & 97.17 & $p=0.034$ \\
\hline Mean time of evaluation (min) & 15.90 & 16.79 & 16.33 & NS \\
\hline
\end{tabular}

COPD chronic obstructive pulmonary disease, NS not significant, min minutes

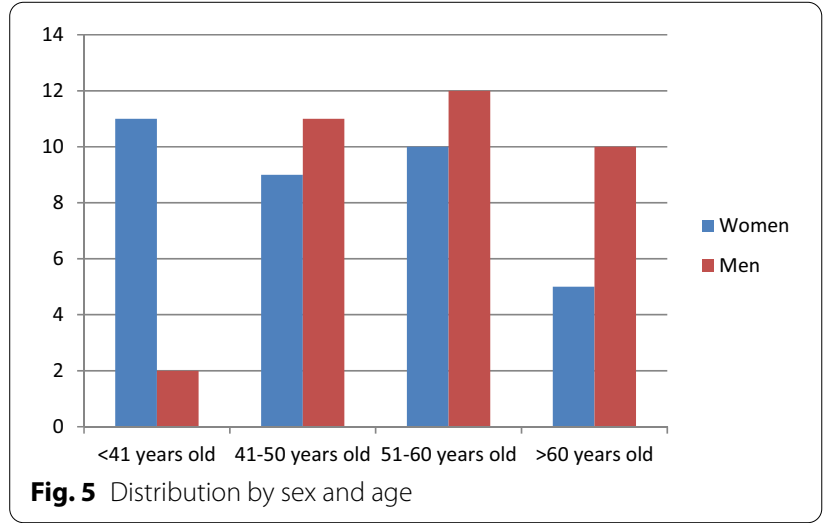

those patients without subpleural consolidation, there was statistical significance as regards the number of fields with an irregular pleural line variable (normal vs. pneumonia, 0.7 vs. 1.83 fields, $p=0.015$ ), with AUC $=0.653 p=0.044$ and with an $S=0.24$ and $\mathrm{Sp}=1$ with a cut-off point in two or more affected fields.

The mean Brixia score for pneumonia was 5.26 out of 18 points (with a range of 2 to 11 points), with no differences between men and women. The mean time required to perform LU was $16.33 \mathrm{~min}$, with no significant differences between sex and the presence of pneumonia.
Table 3 Patients' clinical distribution by the presence of pneumonia

\begin{tabular}{|c|c|c|c|}
\hline & $\begin{array}{l}\text { Pneumonia } \\
(n=40)\end{array}$ & $\begin{array}{l}\text { No } \\
\text { pneumonia } \\
(n=30)\end{array}$ & \\
\hline Age & 55.7 & 47.4 & $p=0.011$ \\
\hline \multicolumn{4}{|l|}{ Sex } \\
\hline Women & 16 & 19 & NS \\
\hline Men & 24 & 11 & \\
\hline Arterial hypertension & 17 & 3 & $p<0.003$ \\
\hline Diabetes mellitus & 7 & 1 & NS \\
\hline Dyslipidaemia & 10 & 2 & NS \\
\hline Smoker & 7 & 6 & NS \\
\hline COPD/asthma & 9 & 6 & NS \\
\hline $\begin{array}{l}\text { Cardiopathy/chronic heart } \\
\text { failure }\end{array}$ & 5 & 2 & NS \\
\hline $\begin{array}{l}\text { Days from the onset of symp- } \\
\text { toms }\end{array}$ & 8.85 & 9.93 & NS \\
\hline Fever & 24 & 16 & NS \\
\hline Dyspnoea & 24 & 15 & NS \\
\hline Cough & 33 & 20 & NS \\
\hline Expectoration & 10 & 4 & NS \\
\hline Pathological lung auscultation & 14 & 6 & NS \\
\hline Oxygen saturation & 96.11 & 97.58 & $p<0.05$ \\
\hline Mean time of evaluation (min) & 16.91 & 15.4 & NS \\
\hline Brixia Index & 5.26 & 0 & $p<0.001$ \\
\hline
\end{tabular}

COPD chronic obstructive pulmonary disease, NS not significant, min minutes

Correlation with prognosis 
Table 4 Main ultrasound findings according to the presence of pneumonia in DT

\begin{tabular}{|c|c|c|c|}
\hline Ultrasound findings & $\begin{array}{l}\text { Pneumonia (\%) } \\
{[S]}\end{array}$ & $\begin{array}{l}\text { No pneumonia (\%) } \\
{[\mathrm{Sp}]}\end{array}$ & $\mathrm{OR},+\mathrm{LR},-\mathrm{LR}$ \\
\hline$\geq 6$ B lines, adding all fields, maximum 4 B lines per lung field & $\begin{array}{l}35 / 40(87.5 \%) \\
{[S=0.875]}\end{array}$ & $\begin{array}{l}5 / 30(16.6 \%) \\
{[S p=0.833]}\end{array}$ & $\begin{array}{l}\mathrm{OR}=35 p<0.001 \\
+\mathrm{LR}=5.25(95 \% \mathrm{Cl} 2.34-11.79) \\
-\mathrm{LR}=0.15(95 \% \mathrm{Cl} 0.07-0.34)\end{array}$ \\
\hline$\geq 4 \mathrm{~B}$ lines or confluent $\mathrm{B}$ lines at least in one lung field & $\begin{array}{l}29 / 40(72.5 \%) \\
{[S=0.725]}\end{array}$ & $\begin{array}{l}5 / 30(16.7 \%) \\
{[S p=0.833]}\end{array}$ & $\begin{array}{l}\mathrm{OR}=13.18 p<0.001 \\
+\mathrm{LR}=4.35(95 \% \mathrm{Cl} 1.91-9.90) \\
-\mathrm{LR}=0.33(95 \% \mathrm{Cl} 0.19-0.56)\end{array}$ \\
\hline$\geq 3 \mathrm{~B}$ lines or confluent $\mathrm{B}$ lines in at least one lung field & $\begin{array}{l}34 / 40(85 \%) \\
{[S=0.85]}\end{array}$ & $\begin{array}{l}11 / 30(36.7 \%) \\
{[S p=0.63]}\end{array}$ & $\begin{array}{l}\mathrm{OR}=9.78 p<0.001 \\
+\mathrm{LR}=2.32(95 \% \mathrm{Cl} 1.42-3.78) \\
-\mathrm{LR}=0.24(95 \% \mathrm{Cl} 0.11-0.52)\end{array}$ \\
\hline $\begin{array}{l}\text { Irregular pleural line in at least } 2 \text { lung fields in absence of sub- } \\
\text { pleural consolidation }\end{array}$ & $\begin{array}{l}13 / 29(44.8 \%) \\
{[S=0.448]}\end{array}$ & $\begin{array}{l}8 / 30(26.7 \%) \\
{[E=0.733]}\end{array}$ & $\begin{array}{l}\mathrm{OR}=2.23 p<0.05 \\
+\mathrm{LR}=1.68(95 \% \mathrm{Cl} 0.82-3.45) \\
-\mathrm{LR}=0.75(95 \% \mathrm{Cl} 0.51-1.11)\end{array}$ \\
\hline Subpleural consolidation & $\begin{array}{l}11 / 40(27.5 \%) \\
{[S=0.275]}\end{array}$ & $0 / 30(0 \%)$ & $\begin{array}{l}\text { +LR: NC } \\
\text {-LR: } 0.72 \text { (95\% Cl 0.60-0.89) }\end{array}$ \\
\hline Condensación & $0 / 40$ & $0 / 30$ & NC \\
\hline Pleural effusion & $6 / 40(15 \%)$ & $2 / 30(6.7 \%)$ & NS \\
\hline
\end{tabular}

DT: digital tomosynthesis; S: sensitivity; Sp: specificity; OR: odds ratio; +LR: positive-likelihood ratio; -LR: negative-likelihood ratio; Cl: confidence interval; NC: not calculable; NS: not significant

No patient with normal DT results required admission or a new consultation in the following 15 days. Of the patients with pneumonia, those who required admission $(n=7)$ had a greater number of B lines than those who did not (25.7 vs. 14.57, $p=0.008$ ). There was one patient with seven B lines and pneumonia who was admitted for a reason other than pneumonia (lung granuloma). No patient with five B lines or fewer was admitted. Of those who were not admitted $(n=63)$, eight were sent to the ED for consultations in the following 15 days (12.7\%) (it was not possible to follow up two patients), and there were no significant differences in the number of B lines of those who had consultations and those who did not (14.6 vs. $9.05 p=0.16)$. Only two patients with five or fewer B lines $(6,7 \%)$ went to the emergency department for consultations in the following 15 days and there was no need for additional treatment. Furthermore, there were six patients with 6 or more B lines $(18,2 \%)$ who had consultations in the following 15 days, all of whom had 16 or more B lines.

An age equal to or greater than 55 was independently associated with hospital admission, with $\mathrm{OR}=9.00$ $(p=0.014)$. No other clinical or ultrasound parameter was associated with admission.

The presence of subpleural consolidation was not associated with admission, but was associated with being sent for a consultation in the ED in the following 15 days $(\mathrm{OR}=10, p=0.025)$. Of the patients who were discharged with a subpleural consolidation, $37.5 \%$ had consultations in the following 15 days, compared to $6 \%$ who were discharged without a subpleural consolidation. Neither the sum of B lines nor any other ultrasound or clinical parameter was associated with consultation in the following 15 days.

Overall, with regard to patients under 55 with $\mathrm{sO}_{2}>95 \%$ and without a subpleural consolidation, the number of B lines had an AUC of 0.972 (95\% CI 0.9191.000) as regards the need for admission, while with a cut-off point of $21 \mathrm{~B}$ lines, the $S$ was 1 and the $E$ was 0.97 . In other words, in this subset of patients, the presence of $<21$ B lines (a maximum of 4 per field) ruled out the need for admission. Only 2 out of 37 patients with these characteristics in our cohort required admission, and had 28 and 29 B lines, respectively.

The patients who required admission $(n=7)$ met at least one of the following criteria: 55 years old or over, $\mathrm{sO}_{2} \leq 95 \%$ and the presence of at least one subpleural consolidation or $\geq 21$ B lines.

\section{Discussion}

The presence of lung involvement in a patient with COVID-19 may be a reason for hospital referral or close follow-up in PC [9]. Its confirmation could, therefore, help physicians during the decision-making process.

This study verifies the good sensitivity and specificity of LU in PC when performed by family physicians with specific training, with results similar to those obtained in studies that have, to date, included patients only in the hospital or residential setting [11] and for whom LU has a considerable inter-observer agreement similar to that attained in other studies [24].

DT rather than CT has been used as a reference test owing to the lower availability of the latter and because its choice is not feasible owing to radiation and access 


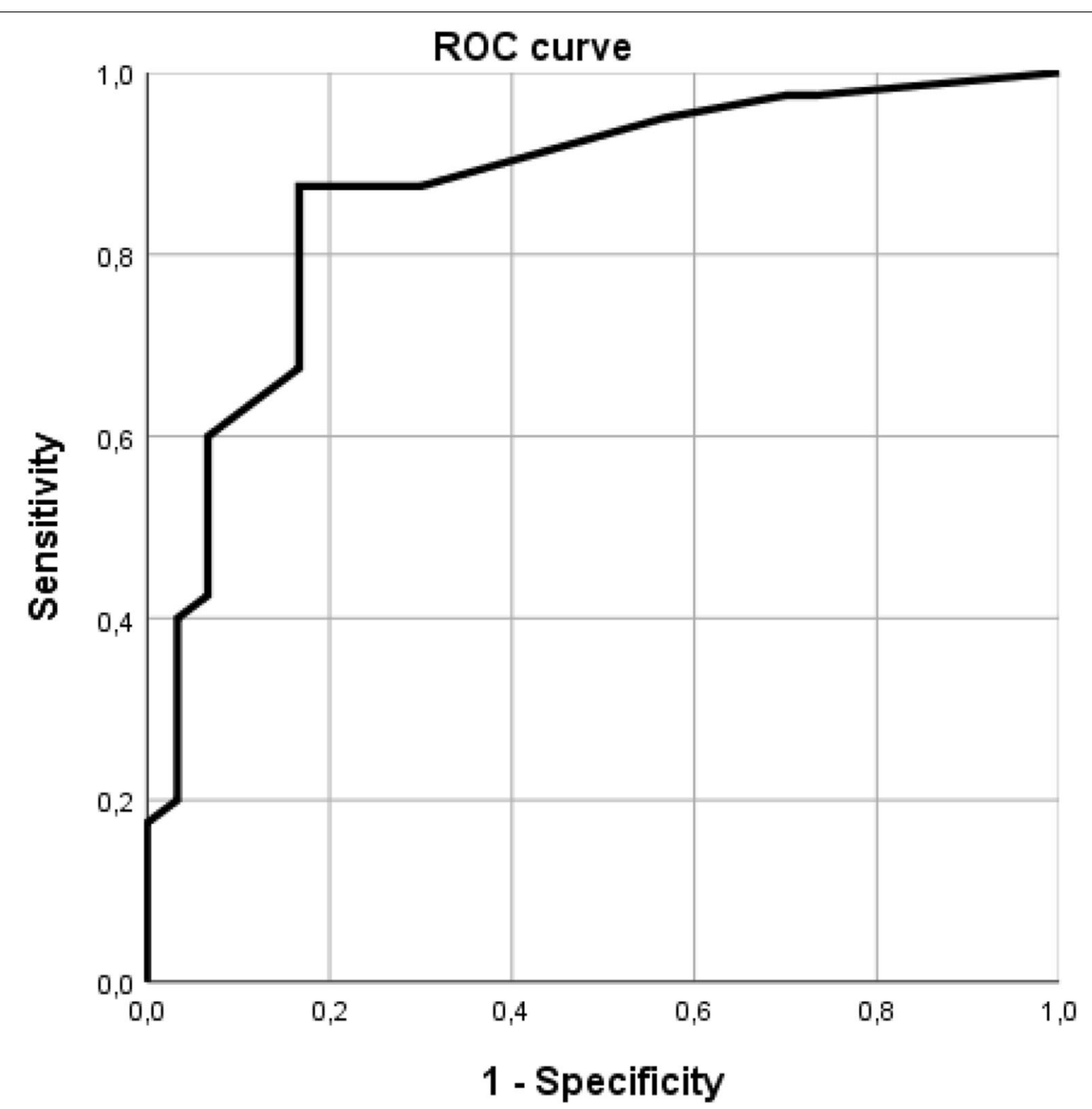

Fig. 6 ROC curve of the sum of the B lines of all the lung fields and pneumonia in digital tomosynthesis. ROC receiver operating characteristic curve

limitation [3]. Moreover, the fact that DT is performed in a specific AP-Rx circuit [16] improves the precision of chest radiography for subtle opacities $[4,5]$, thus making it appropriate for our population in $\mathrm{PC}$, since it is a population with a milder disease. The fact that our population has a milder disease can be confirmed in our study by taking into account variables such as the Brixia Index score, which was low (an average of 5.26 out of 18 points) and a lower number of admissions into the COVID-19 unit and ICU than in other studies $(10 \%$ and $0 \%$ vs. $16 \%$ and $10 \%$ ) [10]. We, therefore, consider that the reference test is valid.

We found that the LU performed best as regards diagnosing COVID-19 pneumonia when a cut-off point was established at six B lines, counting a maximum of four $\mathrm{B}$ lines per field and adding all the fields. If we compare this with considering only four or more B lines or a confluence of B lines in at least one field or 3 or more $B$ lines or a confluence in at least one field, the $S$ and $\mathrm{Sp}$ are lower (see Table 4). It would, therefore, appear reasonable to assume that the performance of $\mathrm{LU}$ in the diagnosis of COVID-19 pneumonia improves when evaluating all lung fields and considering the largest number of artefacts.

We found that the $S$, Sp and AUC $(0.875,0.833$ and 0.87 ) were similar to those attained in other studies in the hospital setting $(S 0.68-1$ and $E 0.546-0.89$ and AUC $0.745-0.866$ ), as were the PPV and NPV (in our study, these were 0.875 and 0.833 , when compared to the $0.54-$ 0.92 and $0.36-0.98$ attained in other studies) $[1,6,10,11$, $17,18,24,25]$. It is necessary to bear in mind that in our study, although there were no differences between the 


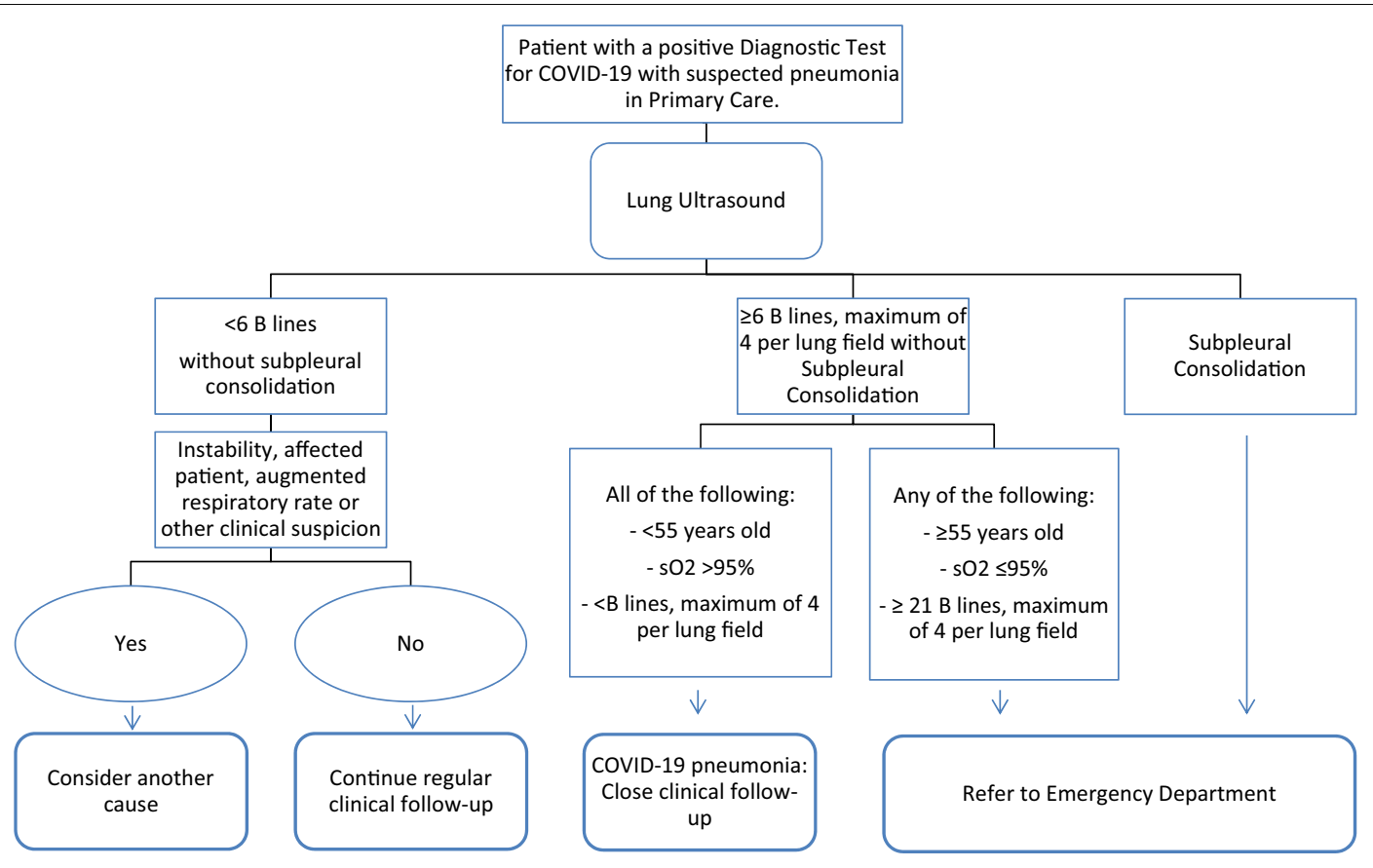

Fig. 7 Management proposal for patients with suspected COVID-19 pneumonia in PC

age groups in terms of AUC, there appears to be a trend towards a higher $S$ and a lower Sp (1 and 0.676) in older patients $(>60)$. This observation coincides with that of another study in nursing homes that found an Sp of 0.48 [26].

Both the number of B lines and the presence of a subpleural consolidation could similarly be correlated with a poor prognosis (more admissions and consultations in the following 15 days, respectively), as found in other studies carried out in PC [9] and in the ED field [10]. Furthermore, the presence of five or fewer B lines rules out the need for admission, although further research is required in order to confirm this. What it is possible to state is that LU could be a valid tool in PC for decision-making and the optimisation of resources, together with the assessment of pulse oximetry and the age of the patient.

The study was developed during the so-called "third wave" of the COVID-19 pandemic. All the patients included had obtained a positive microbiological diagnostic test for coronavirus, and the results should be understood in that context. The external validity of this study is based precisely on the fact that the operators are PC physicians who know the patients' symptoms and the microbiological test and perform the LU, similar to that which occurs in clinical practice in PC.
The limitations of this study include the following. First, although DT is a promising diagnostic tool $[4,5]$, it has yet to be well studied in the context of COVID19 pneumonia. Second, as any patient with COVID-19 infection may have lung involvement, it is necessary to take into account that this study has been carried out only with patients with specific symptoms suggesting the need for hospital management. Another important limitation is that immobilised or institutionalised patients were not included, signifying that other studies would be necessary in order to corroborate validity as regards these PC patients.

Bearing our results in mind, once COVID-19 pneumonia is suspected, the most important clinical variables for the diagnosis of or the need for admission are age, oxygen saturation and lung ultrasound. We, therefore, propose the following management algorithm for suspected COVID-19 pneumonia in PC (Fig. 7).

\section{Conclusions}

Point-of-care ultrasound in primary care has good sensitivity and specificity when compared to digital tomosynthesis as regards the diagnosis of COVID-19 pneumonia in patients with the clinical suspicion of pulmonary involvement. In the case of these patients in particular, clinical ultrasound findings could, along with age and oxygen saturation, improve decision-making in primary care. We propose a management algorithm for 
these patients, and as future work, there is a need to confirm its usefulness and as regards developing statistical models with which to diagnose COVID-19 pneumonia and predict its severity. Further research is particularly required for elderly and immobilised patients in the primary care setting.

\begin{abstract}
Abbreviations
+LR: Positive-likelihood ratio; -LR: Negative-likelihood ratio; AP-Rx: Specific high-resolution circuit between primary care and the radiology department; AUC: Area under the curve; Cl: Confidence interval; COVID-19: Coronavirus disease 19; CT: Computed tomography; DT: Digital tomosynthesis; ED: Emergency department; LU: Lung ultrasound; NPV: Negative predictive value; OR: Odds ratio; PC: Primary care; PPV: Positive predictive value; ROC: Receiver operating characteristic; S: Sensitivity; Sp: Specificity; $\mathrm{SO}_{2}$ : Oxygen saturation.
\end{abstract}

\section{Acknowledgements}

Special thanks to Isabel María Hidalgo García, Pablo Ireno Fernández Pérez and the whole group of Family Doctors from Archena Health Centre, Vistalegre-La Flota Health Centre. Special thanks to Carmen Moreno Barba, Rafael Pérez Costa as well to the whole group of doctors in the Emergency Department and Radiology Department of Morales Meseguer Hospital. This work has been sponsored by the Spanish Ministry of Universities by means of the Margarita Salas program and by the project UMU-CAMPUS LIVING LAB EQC2019006176-P funded by ERDF funds.

\section{Authors' contributions}

PFO: the main author of the study, contributed to the design and strategy and execution of the research, patient assessment, data collection, statistical analysis, results interpretation and confection of the manuscript. NAL: contributed to the conception and design of the study, to the implementation of the research, data collection and subsequent analysis and interpretation of the results as well as to the writing of this document. SCG: contributed to the conception and design of the study, data collection and subsequent analysis and interpretation as well as to the writing and critical review of the manuscript after its completion. LM: contributed to the design and implementation of the research, to the analysis of the results and to the writing of the manuscript. AG-V: contributed to the statistical design, implementation of the statistical analysis and interpretation of the results as well as to review the manuscript. All authors read and approved the final manuscript.

\section{Availability of data and materials}

The datasets used and/or analysed during the current study are available from the corresponding author on reasonable request.

\section{Declarations}

Ethics approval and consent to participate

This study was approved by the HUMM Clinical Research Ethics Committee (EST code: 51/20) and was carried out after signing the informed consent.

\section{Consent for publication}

Not applicable.

\section{Competing interests}

All the authors declare no conflict of interests.

\section{Author details}

'Vistalegre-La Flota Health Centre, Paseo Ing. Sebastián Feringán, 18, 30007 Murcia, Spain. ${ }^{2}$ Mario Spreáfico-Archena Health Centre, Archena, Murcia, Spain. ${ }^{3}$ Department of Information and Communication Engineering Faculty of Computer Sciences, University of Murcia, Murcia, Spain.

Received: 21 June 2021 Accepted: 11 January 2022

Published online: 22 February 2022

\section{References}

1. Tung-Chen Y, Algora-Martín A, Llamas-Fuentes R, Rodríguez-Fuertes P, Martínez Virto AM, Sanz-Rodríguez E et al (2021) Point-of-care ultrasonography in the initial characterization of patients with COVID-19. Med Clín 156(10):477-484

2. Ai T, Yang Z, Hou H, Zhan C, Chen C, Lv W et al (2020) Correlation of chest CT and RT-PCR testing in coronavirus disease 2019 (COVID-19) in China: a report of 1014 cases. Radiology 296(2):E32-E40

3. Revel M-P, Parkar AP, Prosch H, Silva M, Sverzellati N, Gleeson F et al (2020) COVID-19 patients and the radiology department-advice from the European Society of Radiology (ESR) and the European Society of Thoracic Imaging (ESTI). Eur Radiol 20:1-7

4. Calvo I, SantaCruz-Calvo S, Aranzana MG, Mármol P, Luque JÁ, Peral I et al (2020) Digital tomosynthesis and COVID-19: an improvement in the assessment of pulmonary opacities. Arch Bronconeumol 56(11):761-763

5. Choo JY, Lee KY, Yu A, Kim J-H, Lee SH, Choi JW et al (2016) A comparison of digital tomosynthesis and chest radiography in evaluating airway lesions using computed tomography as a reference. Eur Radiol 26(9):3147-3154

6. Tung-Chen Y, Martí de Gracia M, Díez-Tascón A, Alonso-González R, Agudo-Fernández S, Parra-Gordo ML et al (2020) Correlation between chest computed tomography and lung ultrasonography in patients with coronavirus disease 2019 (COVID-19). Ultrasound Med Biol 46(11):2918-2926

7. Lopes AJ, Mafort TT, da Costa CH, Rufino R, de Cássia Firmida M, Kirk KM et al (2020) Comparison between lung ultrasound and computed tomographic findings in patients with COVID-19 pneumonia. J Ultrasound Med 40(7):1391-1399

8. Volpicelli G, Cardinale L, Fraccalini T, Calandri M, Piatti C, Geninatti C et al (2021) Descriptive analysis of a comparison between lung ultrasound and chest radiography in patients suspected of COVID-19. Ultrasound J 13:1-11

9. Calvo-Cebrián A, Alonso-Roca R, Rodriguez-Contreras FJ, RodríguezPascual MDLN, Calderín-Morales MDP (2021) Usefulness of lung ultrasound examinations performed by primary care physicians in patients with suspected COVID-19. J Ultrasound Med 40(4):741-750

10. Volpicelli G, Gargani L, Perlini S, Spinelli S, Barbieri G, Lanotte A et al (2021) Lung ultrasound for the early diagnosis of COVID-19 pneumonia: an international multicenter study. Intensive Care Med. https://doi. org/10.1007/s00134-021-06373-7

11. Islam N, Ebrahimzadeh S, Salameh J-P, Kazi S, Fabiano N, Treanor L et al (2021) Thoracic imaging tests for the diagnosis of COVID-19. Cochrane Database Syst Rev. https://doi.org/10.1002/14651858.CD013639.pub4/ full

12. Ferrari A, Bertolaccini L, Solli P, Di Salvia PO, Scaradozzi D (2018) Digital chest tomosynthesis: the 2017 updated review of an emerging application. Ann Transl Med 6(5):91

13. Vikgren J, Zachrisson S, Svalkvist A, Johnsson AA, Boijsen M, Flinck A et al (2008) Comparison of chest tomosynthesis and chest radiography for detection of pulmonary nodules: human observer study of clinical cases. Radiology 249(3):1034-1041

14. Gunnell ET, Franceschi DK, Inscoe CR, Hartman A, Goralski JL, Ceppe A et al (2019) Initial clinical evaluation of stationary digital chest tomosynthesis in adult patients with cystic fibrosis. Eur Radiol 29(4):1665-1673

15. Murcia C de SR de. Murciasalud. Centros Sanitarios. http://www.murci asalud.es/caps.php?op=mostrar_area\&id_area $=6 \& i d s e c=4294$. Accessed 27 Mar 2021

16. García Santos JM, Plasencia Martínez JM, Fabuel Ortega P, Lozano Ros M, Sánchez Ayala MC, Pérez Hernández G et al (2021) Radiology departments as COVID-19 entry-door might improve healthcare efficacy and efficiency, and emergency department safety. Insights Imaging 12(1):1

17. Zieleskiewicz L, Markarian T, Lopez A, Taguet C, Mohammedi N, Boucekine M et al (2020) Comparative study of lung ultrasound and chest computed tomography scan in the assessment of severity of confirmed COVID-19 pneumonia. Intensive Care Med 29:1-7

18. Peyrony O, Marbeuf-Gueye C, Truong V, Giroud M, Rivière C, Khenissi $K$ et al (2020) Accuracy of emergency department clinical findings for diagnosis of coronavirus disease 2019. Ann Emerg Med 76(4):405-412

19. Volpicelli G, Lamorte A, Villén T (2020) What's new in lung ultrasound during the COVID-19 pandemic. Intensive Care Med 4:1-4 
20. Borghesi A, Zigliani A, Golemi S, Carapella N, Maculotti P, Farina D et al (2020) Chest X-ray severity index as a predictor of in-hospital mortality in coronavirus disease 2019: a study of 302 patients from Italy. Int J Infect Dis 96:291-293

21. Borghesi A, Maroldi R (2020) COVID-19 outbreak in Italy: experimental chest $X$-ray scoring system for quantifying and monitoring disease progression. Radiol Med 1:1-5

22. Tanis EA, Hogg RV (2010) Data CD [to accompany] Probability and statistical inference, 8th edn. Pearson, Upper Saddle River

23. Landis JR, Koch GG (1977) The measurement of observer agreement for categorical data. Biometrics 33(1):159

24. Fonsi GB, Sapienza P, Brachini G, Andreoli C, Cicco MLD, Cirillo B et al (2021) Is lung ultrasound imaging a worthwhile procedure for severe acute respiratory syndrome coronavirus 2 pneumonia detection? J Ultrasound Med. https://doi.org/10.1002/jum.15487

25. Bar S, Lecourtois A, Diouf M, Goldberg E, Bourbon C, Arnaud E et al (2020) The association of lung ultrasound images with COVID-19 infection in an emergency room cohort. Anaesthesia 75(12):1620-1625

26. Dini FL, Bergamini C, Allegrini A, Scopelliti M, Secco G, Miccoli M et al (2020) Bedside wireless lung ultrasound for the evaluation of COVID-19 lung injury in senior nursing home residents. Monaldi Arch Chest Dis. https://doi.org/10.4081/monaldi.2020.1446

\section{Publisher's Note}

Springer Nature remains neutral with regard to jurisdictional claims in published maps and institutional affiliations.

\section{Submit your manuscript to a SpringerOpen ${ }^{\circ}$ journal and benefit from:}

- Convenient online submission

- Rigorous peer review

- Open access: articles freely available online

- High visibility within the field

- Retaining the copyright to your article

Submit your next manuscript at $\gg$ springeropen.com 